\title{
A NEUROCIÊNCIA E AS MÚLTIPLAS REPRESENTAÇÕES: POSSÍVEIS CONVERGÊNCIAS PARA O ENSINO DE CIÊNCIAS
}

\author{
Mário Sérgio Nunes Bica* \\ Pâmela Billig Mello-Carpes** \\ Rafael Roehrs ${ }^{* * *}$
}

\begin{abstract}
Resumo: O ensino de ciências pressupõe um conjunto de diferentes símbolos e formas de comunicação, por conta disso, torna-se questionável um esquema educacional baseado num único formato representativo. Conforme apontam programas internacionais de avaliação e as nossas diretrizes curriculares, o processo para aprender ciência envolve um desafio representacional em uma variedade de contextos. Nesse sentido, existe uma linha de investigação da área do ensino de ciências, denominada Múltiplas Representações, que defende a utilização de diferentes formas de comunicação no processo de ensino e aprendizagem. Estudos recentes da neurociência apontam alguns resultados que se inserem nessa perspectiva, relacionando conhecimentos fundamentais das bases neurobiológicas da aprendizagem, da memória, das emoções, sobretudo respeitando a individualidade cognitiva dos alunos. Esse trabalho apresenta pontos de convergência entre referenciais do ensino de ciências e postulados do campo da neurociência, em que ambos podem vir a amparar e contribuir sobre o processo da prática docente no ensino de ciências.
\end{abstract}

Palavras-chave: Neurociência. Múltiplas Representações. Ensino de Ciências. Cognição. Memória.

\section{Introdução}

O discurso científico que compõe o dia-a-dia no contexto didático-pedagógico escolar é permeado de sons, gestos, falas, expressões faciais, textos, jogos, atividades práticas, vídeos e imagens que possibilitam uma interface com as experiências anteriores de cada estudante (SANGIOGO; MARQUES, 2015). Essas diferentes ações didáticas são representações que podem complementar, confirmar ou reforçar conhecimentos anteriores de cada aluno, de modo a sustentar uma aprendizagem significativa, quando utilizados de forma integrada (AINSWORTH, 1999; MOREIRA; MANSINI, 2009).

\footnotetext{
* Mestrando do Programa de Pós Graduação em Educação em Ciências: Química da Vida e Saúde, Universidade Federal do Pampa, campus Uruguaiana, RS, Brasil.

** Professora Associada da Universidade Federal do Pampa, Líder do Grupo de Pesquisa em Fisiologia, Bolsista de Produtividade em Pesquisa 1D do CNPQ, Fellow Science of Learning IBRO/IBE - UNESCO.

*** Doutor em Química pela Universidade Federal de Santa Maria, RS. Professor Adjunto da Universidade Federal do Pampa, Líder do Grupo Interdisciplinar de Pesquisa em Prática de Ensino.
} 
Referenciais teóricos da área do ensino de ciências, como a linha de investigação das Múltiplas Representações, defendem a utilização de diferentes formas de comunicação no processo de ensino e aprendizagem que respeitam a individualidade cognitiva dos alunos (AINSWORTH, 1999). Da mesma forma, estudos recentes da neurociência apontam resultados que se inserem nessa perspectiva, relacionando conhecimentos fundamentais das bases neurobiológicas da aprendizagem, da memória, das emoções e de outras funções cerebrais que são estimuladas durante a práxis docente em sala de aula (CAMPOS, 2010; FREITAS; MOTTA; MELLO-CARPES, 2015).

Nesse sentido, uma importante relação que se estabelece no processo didático pedagógico é o conceito de memória, onde Iván Izquierdo afirma que:

Memória significa aquisição de informações [...] a aquisição é também chamada de aprendizado [...] só se 'grava' aquilo que foi aprendido [...] a evocação é também chamada de lembrança [...] só lembramos aquilo que gravamos aquilo que foi aprendido (IZQUIERDO, 2011, p. 11).

É importante destacar que o conjunto de nossas memórias faz com que cada um de nós seja um indivíduo único, um ser para o qual não existe outro idêntico. Significa que o ambiente, e nesse caso podemos mencionar o próprio ambiente escolar, deve proporcionar condições para que o processo de aprendizagem seja potencializado em cada sujeito, pois nossas memórias são moduladas pelas emoções, pelo nível de consciência e pelo estado de ânimo de cada indivíduo (IZQUIERDO, 2011).

O processo de ensino e aprendizagem formal ocorre durante um extenso período da vida de cada pessoa no contexto escolar básico e superior, e esse processo de troca ou medição é estabelecido pelo professor, que durante sua prática docente se depara com diferentes capacidades, tanto cognitivas, emocionais, sociais, físicas, como morais (CAMPOS, 2010). Refletindo sobre essa realidade, cada forma de comunicação deve ser aproveitada no âmbito educacional a fim de potencializar as competências e habilidades cognitivas individuais (KLEIN; LABURÚ, 2012).

O ensino de ciências tem como objetivo possibilitar aos estudantes a compreensão das interações entre ciência, tecnologia e sociedade, e desenvolver a capacidade de resolução de problemas e tomada decisões relativas às questões (socioambientais) com as quais se deparam como cidadãos (SILVA; MARCONDES, 2015). Porém, o ensino das ciências da natureza em âmbito nacional tem encontrado dificuldades em otimizar o processo de ensino e aprendizagem nas escolas (PISA, 2012). Uma das grandes dificuldades é fazer com que os estudantes apropriem-se dos diferentes instrumentos e dos símbolos utilizados para representar o discurso científico (LABURÚ; BARROS; SILVA, 2011). O professor é o 
principal responsável pela função de auxiliar o indivíduo a perceber e interpretar esse discurso, sendo necessário o planejamento e utilização de diferentes modos de representação conceitual, com maior ou menor proximidade aos conceitos específicos da ciência, como práticas em laboratório, jogos, estímulo à leitura, à expressão oral, entre outros modos (LABURÚ; BARROS; SILVA, 2011).

Nesse trabalho apresentamos pontos de convergência entre referenciais da linha de investigação das múltiplas representações indo ao encontro de postulados do campo da neurociência, em que essa apresenta fundamentos baseados em estudos científicos que justificam os pressupostos defendidos e explicam os resultados observados no uso das múltiplas representações no ensino de ciências.

\section{Múltiplas representações e aspectos da memória}

É preciso deixar claro que a interface estabelecida entre estudos no ensino de ciência e referenciais das bases neurobiológicas da aprendizagem e memória não busca modificar ou substituir conceitos de cunho pedagógico com os quais os profissionais da educação estão familiarizados. Aprendizagem não é necessariamente sinônimo de memória, mas sim um processo complementar, onde a memória pode ser vista como um processo neurobiológico que permite a aprendizagem, e vice-versa (CARVALHO, 2011; LENT, 2010).

Tanto a linha de investigação das múltiplas representações (AINSWORTH, 1999) quanto os postulados da neurociência para a educação (FERNANDES et al., 2015) indicam que cada sujeito possuiu um intricado sistema que opera nos níveis neurais e cognitivos, que atua como fator determinante no processo de ensino e aprendizagem (FRITH; MAGUIRE; BISHOP, 2011). A utilização de diferentes representações no ensino, portanto, vai ao encontro a essa grande diversidade de estudantes que compõem uma sala de aula, em que cada sujeito tem suas próprias representações, que foram reunidas com base na sua própria experiência, suas memórias individuais. Conforme Chiesa (2012, p. 43), “esse sistema organizado traduz o mundo externo para a percepção individual e governa o processo de raciocínio de cada um de nós".

O ensino de ciências pressupõe um conjunto de diferentes símbolos e formas de comunicação (LABURÚ; BARROS; SILVA, 2011), já que a linguagem humana é única na natureza e rica em sua capacidade de simbolizar pensamentos. No entanto, a expressão da linguagem não parece anteceder a formação do sistema mnemônico, ou seja, a constituição da memória de cada pessoa. Sabe-se que existem diferentes tipos de memórias, umas são mais 


\section{\#tear}

visuais, outras olfativas, motoras, algumas se associam a memórias preexistentes, e outras não requerem nenhum conhecimento prévio (LENT, 2010). Uma vez consolidadas, as memórias podem ser evocadas (lembradas) quando o sujeito percebe algum estímulo que se relacione com o recebido no momento da aquisição da memória (aprendizagem) (IZQUIERDO, 2011).

Quando queremos lembrar alguma informação sobre o meio que nos rodeia, nossos neurônios reconvertem sinais bioquímicos em elétricos, e vice-versa, por meio de sinapses químicas e potenciais bioelétricos ao longo de uma rede neural para que possamos interpretálas (LENT, 2010). Diferentes modos de linguagem envolvem sistemas semelhantes de expressão e compreensão, já que o nosso sistema nervoso extrai e traduz as informações que adquirimos pelos órgãos sensoriais (visão, audição, tato, etc.), pois, segundo Izquierdo (2011, p. 21): “os códigos e processos utilizados pelos neurônios não são idênticos à realidade da qual extraem ou à qual revertem as informações". No entanto, essa codificação é bastante específica, de forma que, mesmo que os sinais sensoriais sejam todos convertidos em estímulos elétricos e químicos, nosso cérebro é capaz de identificar os diferentes tipos de informações (visual, auditiva, tátil, etc.), isto porque a origem do sinal codificado é percebida, este sinal segue vias neurais específicas e tem um destino específico (vai seguir até áreas corticais primárias e secundárias específicas) (MELLO-CARPES; LARA, 2012). Seja através da leitura de um livro, uma informação olfativa que penetra o nariz do indivíduo, a gustação pela boca, quando que diferentes vias neurais são estimuladas, há regiões do cérebro onde essas vias convergem, e essas regiões são responsáveis pela formação de memórias (IZQUIERDO, 2011). A interpretação das informações recebidas, posteriormente, requer a integração dos diferentes tipos de informação em áreas corticais terciárias do cérebro (LENT, 2010).

A linha de investigação das Múltiplas Representações afirma que uma nova representação convém para complementar, confirmar, ou reforçar conhecimentos passados, já que uma nova representação propicia restrição e refinamento de uma interpretação (AINSWORTH, 1999). A prática da repetição de uma informação (reexposição a ela) em diferentes modos no processo de ensino de ciências permite ao estudante encontrar diferentes caminhos simbólicos para identificar ou dar um novo sentido a um conceito prévio (KLEIN; LABURÚ, 2012). Esta variabilidade de formas de rever o mesmo conteúdo pode potencializar o aprendizado, já que mobiliza diferentes vias neurais, as quais são conjuntamente processadas em áreas terciárias do córtex cerebral. Conforme Laburú, Barros e Silva: 


\section{\#tear}

[...] a pluralidade de modos e a multiplicidade de formas de representação, permitem a formação de pontes entre os conhecimentos prévios do sujeito e os novos conceitos, possibilitando a estruturação de sentidos e de relações argumentativas (LABURÚ; BARROS; SILVA, 2011, p. 481).

Esta relação entre conhecimentos prévios e conhecimentos novos, que estão sendo construídos, é um aspecto importante. Estudos recentes demonstram que, quando os estudantes ativamente mobilizam conhecimentos prévios relacionados ao conteúdo que está sendo trabalhado inicia-se o processo de reconsolidação da memória, o qual desencadeia uma série de processos neuroquímicos que estimulam a neuroplasticidade sináptica, permitindo o fortalecimento ou ampliação dos conhecimentos do aprendente (SOSA et al., 2018; KLEIMAN et al., 2017; KHOIRIYAH et al., 2015).

Portanto, o planejamento que inclui somente uma maneira de representar os conceitos científicos tende a tornar-se limitado, tanto em relação aos caminhos que devem ser percorridos durante esse processo de ensino e aprendizagem, assim como torna limitado os estímulos neurais fundamentais para a aquisição, reconsolidação e evocação dos conceitos mais significativos (FERNANDES et al., 2015). A repetição de conceitos, vista na perspectiva multirepresentacional, como aquelas que incluem imagens, gráficos, utilização de gestos, atividade motora, observação e manipulação de objetos, aponta, portanto, uma interface com o discurso neurocientífico (ZOMPERO; GONÇALVES; LABURÚ, 2017).

Sabe-se que para uma maior fidelidade à memória evocada, a que se pretende recordar, é preciso apresentar um maior número possível de componentes do estímulo/informação inicial, pois esses diferentes estímulos podem contribuir com a assimilação, bem como com a recordação desta informação (IZQUIERDO, 2011). Portanto, o enriquecimento representacional implica diferentes caminhos e estímulos para que o estudante busque, através de seus conhecimentos prévios, rever e reconsolidar seu aprendizado. Em termos neurobiológicos, a cada momento em que o estudante revê o conteúdo em questão, a(s) sinapses(s) na(s) qual(is) este conteúdo está "arquivado" são mobilizadas, e tornam-se lábeis, ou seja, sujeitas a modificação (neuroplasticidade), de tal forma, que podem ser fortalecidas (reconsolidação), contribuindo para a melhor aprendizagem do conteúdo.

Além disso, é preciso ressaltar que o método utilizado a cada retomada de um determinado conteúdo é recebido de forma muito individual por cada estudante, gerando em cada um, diferentes níveis de motivação e diferentes emoções. As emoções constituem requisito fundamental para o processo de aprendizagem e formação de memórias, pois os neurônios que regulam aspectos dos diferentes tipos de emoções possuem conexões diretas com neurônios relacionados à formação de memórias (FREITAS; MOTTA; MELLO- 


\section{\#tear}

CARPES, 2015). Nesse viés, cabe ao educador (re) pensar as escolhas de suas estratégias metodológicas, atribuindo a sua prática dinamismo e prazer, ou seja, uma prática pedagógica sobre um contexto emocional (FREITAS; MOTTA; MELLO-CARPES, 2015).

\section{A neurociência e a escolha dos métodos e materiais de ensino}

Quanto mais recursos forem empregados na comunicação de uma informação, maiores as chances dela se tornar uma memória de longa duração (HERCULANO-HOUZEL, 2009). Através da utilização de vários recursos e estratégias metodológicas é possível alcançar um maior envolvimento de áreas corticais primárias, tais como a somestésica, a auditiva e visual, que devem auxiliar na associação de informações para a memória e a cognição (LENT, 2010).

As associações ocorrem através da atividade de diferentes sistemas, por exemplo, através da oralidade, a compreensão ocorre através do sistema auditivo, enquanto para a gestualidade, a compreensão se realiza pelo sistema visual. Já para a expressão escrita convencional é o sistema visual que realiza a compreensão, enquanto à forma escrita Braile é o sistema somestésico que se encarrega da tarefa (LENT, 2010). Sobre essa ótica da neurociência é que a linha de investigação das múltiplas representações (AINSWORTH, 1999) se apresenta como uma importante estratégia metodológica para o ensino de ciências (LABURÚ; BARROS; SILVA, 2011).

Cada representação envolve processos cognitivos que são mais ou menos fáceis de realizar em um sistema de símbolos do que em outros, por vezes, podendo ser somente um único sistema (LABURÚ; BARROS; SILVA, 2011). A fala, por exemplo, é composta de segmentos que seguem uma temporalidade linear, já a utilização de um gesto tem seu significado derivado de um todo, enquanto figuras ou esquemas têm a característica de representar várias relações entre os elementos que constituem um objeto ou situação (LABURÚ; BARROS; SILVA, 2011).

Atividades de reconhecimento e manipulação de objetos envolvem, além de uma via (ventral) de análise cognitiva desses objetos, também outra via (dorsal) pragmática, que visa orientar o corpo (a motricidade) do sujeito. Isso significa que a aprendizagem motora também é parte importante do aprendizado, pois envolve um grande número de neurônios espelhos ligados as nossas ações de observação visual, imitação motora de outras pessoas (inclusive o professor) e aquisição da linguagem (LENT, 2010).

Assim, o planejamento de uma aula deve considerar a escolha consciente de métodos de ensino. A inserção de atividades lúdicas, por exemplo, tais como a prática de jogos com 
regras determinadas, geralmente implica em prazer, divertimento e ainda, uma maior voluntariedade de participação por parte dos estudantes. Cabe salientar que entre todas as características elencadas nessa prática, a presença ou ausência de regras está intimamente ligada ao uso de jogos ou atividades lúdicas, pois implicam em um "contrato social" de convivência entre os participantes. (SOARES, 2008). É possível que os estudantes sintam-se instigados a manter maior atenção na atividade proposta, indo para além de um estado de atenção explícita (visual e involuntária), em que o aluno estaria "fingindo" prestar atenção a determinada situação, partindo para um estado de atenção implícita (voluntária), em que de fato esse sujeito estaria interessado em ser participante no processo de ensino (LENT, 2010). A construção de materiais didáticos também se apresenta como uma alternativa eficaz aos professores de ciências. A produção de seu próprio material instrucional pode conferir, ao professor, segundo Silva e Marcondes (2015, p. 81), “maior autonomia pedagógica, talvez até maior criticidade em relação aos livros didáticos, além de contribuir para o aumento da autoestima".

Ainda no processo da prática pedagógica muito se discute a respeito da realização de atividades que buscam estimular a expressão oral e verbal dos estudantes (UCHO; FRANCISCO JUNIOR; FRANCISCO, 2012). Nesse sentido, referenciais da neurociência afirmam que ao se expressar através da fala o aluno necessita consultar um léxicon ${ }^{1}$ em busca de informações semânticas e fonológicas necessárias à expressão verbal (LENT, 2010). A construção de uma frase em nível de pensamento (sem emissão da fala) busca formar a mensagem (fonemas e regras sintáticas), e parece envolver a região frontal lateral inferior conhecida como área de Broca, localizada no hemisfério esquerdo da maioria das pessoas (LENT, 2010).

Já no momento da emissão da fala, também denominada como articulação, são as regiões pré-motoras do córtex frontal esquerdo que estão sendo estimuladas, assim como setores de representação da face, localizadas no giro pré-central de ambos os hemisférios (LENT, 2010). Com isso, o estudante consulta seu sistema mnemônico (a sua memória), e essa consulta é realizada em diferentes regiões corticais do nosso cérebro. Ao construir um pensamento ou uma frase, é a área de Broca que está sendo envolvida, já quanto à compreensão do que está sendo dito, ou ouvido é função da área de Wernicke, e ambas devem estar conectadas através de um feixe de fibras denominado feixe arqueado, para que os

${ }^{1}$ Conjunto de palavras reunidas em alguma ordem (LENT, 2010). 
indivíduos possam entender o que estão falando, ou compreender o que outros the falam (LENT, 2010).

Atividades que visam expressão gestual também podem ser planejadas sob a perspectiva da neurociência com o intuito do desenvolvimento de nuances e entonações de voz que conferem a fala humana um conteúdo emocional capaz de modificar o sentido racional das frases (LENT, 2010). Diferenciamo-nos de um robô através das inflexões da voz, em uma mímica facial e em gestos das mãos e do corpo, que são aspectos emocionais da fala conhecidos como prosódia que, na maioria das pessoas, ativam áreas pertencentes ao hemisfério direito, localizando-se nas mesmas regiões que no lado esquerdo processam os aspectos cognitivos da linguagem (LENT, 2010).

Estudos da neurociência também sugerem que diferentes oportunidades de aprendizado na infância se correlacionam com diferenças neurais que podem contribuir para aprendizagens futuras. A utilização de formas variadas de ensino, tais como o ensino informal, em que o estudo ocorre fora do ambiente escolar pode promover uma maior participação e elevar a motivação dos alunos. Cabe nesse sentido, o uso de tecnologias como importante aliado, pois os estudantes podem sentir-se inseridos, ou ligados a assuntos escolares em momento extraclasse, já que passam aproximadamente $70 \%$ do seu tempo fora do ambiente escolar (MELTZOFF et al., 2009). Dessa forma, uma atividade experimental não implica necessariamente o trabalho em laboratório, certas atividades de trabalho prático podem assumir características de trabalho experimental, como o de uma visita a um museu, por exemplo (PEREIRA; MOREIRA, 2017).

Atividades de caráter investigativo e problematizador podem viabilizar a relação entre aspectos teóricos e empíricos, facilitando, por exemplo, o domínio da linguagem científica (PEREIRA; MOREIRA, 2017; ZOMPERO; GONÇALVES; LABURÚ, 2017). Smartphones, e televisores estão cada vez mais integrados entre si e à rede mundial de computadores, e inevitavelmente, conforme Pereira e Moreira:

A escola e as mudanças tecnológicas devem estreitar relações [...] onde as atividades prático experimentais desempenhem funções sociais relevantes para os estudantes ao estarem vinculadas de fato a um projeto educacional. (PEREIRA e MOREIRA, 2017, p. 274).

Garvett, Dolan e Behrns (2017) apresentam um estudo que descreve o córtex entorrinal, uma região formada por neurônios que auxiliam na nossa capacidade de nos situar no espaço. Essa região está ligada a outra área importante sobre a consolidação de memória, o hipocampo. Juntos formam o sistema entorrinal-hipocampal, que responde de forma positiva à aprendizagem de estímulos associados e em sequência objetiva. Ou seja, o sistema entorrinal- 
hipocampal responde à violação de estruturas de sequências aprendidas e sinaliza a probabilidade de eventos em sequências aprendidas (GARVETT; DOLAN;e BEHRNS, 2017). Assim, a opção da utilização de mapas que apresentem conceitos de maneiras objetiva, hierárquica e associativa, como mapas conceituais (MOREIRA; MANSINI, 2009) podem auxiliar os estudantes a compreender melhor e ainda promover a ele intuição a novos conceitos relacionados ao conteúdo (GARVETT; DOLAN; BEHRNS, 2017).

Outra modalidade, ainda pouco explorada no ensino de ciências, é a utilização de histórias em quadrinhos. Essas podem atingir diferentes faixas etárias, consequentemente, níveis escolares, e vêm sendo utilizadas como ferramenta na educação em ciências em diferentes contextos (UCHO; FRANCISCO JUNIOR; FRANCISCO, 2012). No caso específico dos quadrinhos, Luyten $(2011$, p.6) assinala que "as imagens apoiam o texto e dão aos alunos pistas contextuais para o significado da palavra". Dehaene e Cohen (2011) em seu trabalho apresentam dados interessantes sobre o processo de aprendizado da leitura, e como esse processo modifica determinadas áreas corticais, especialmente, o sulco ventral occiptotemporal esquerdo. No entanto, salienta que a questão do processo visual deve conter significados simbólicos para promover alguma alteração, nessa que parece ser uma área estritamente ligada à linguagem (DEHAENE; COHEN, 2011).

Para o entendimento de fenômenos não observáveis, a ciência por muitas vezes também acaba utilizando-se de comparações para tornar o entendimento mais palpável ao público leigo (CARMO, 2006; SILVA; TERRAZAN, 2005). O uso de analogias se estrutura, principalmente, em dois domínios: o análogo que representa o conhecimento familiar aos alunos, e o alvo (ou específico), que representa o conhecimento abstrato vinculado ao discurso científico (BARBOSA et al., 2012). Conforme teóricos da área da neurociência apontam, cada sujeito inserido em uma sala de aula traz consigo um sistema organizado de imagens e representações (FRITH; MAGUIRE; BISHOP, 2011). Dessa forma, a analogia como recurso deve almejar a elucidação para determinado grupo de conceitos científicos, unindo-se ao conhecimento prévio do estudante (BARBOSA et al., 2012).

\section{Planejamento multimodal e as funções executivas}

Conforme apontam programas internacionais de avaliação e as diretrizes curriculares para o ensino de ciências, o processo para aprender ciência envolve um desafio representacional em uma variedade de contextos (BRASIL, 2013; PISA, 2012). É necessário que esse processo esteja contemplando o desenvolvimento cognitivo dos sujeitos envolvidos, 


\section{\#tear}

de forma que os estudantes devem demonstrar habilidades como identificar questões e evidências, elaborar, avaliar e comunicar conclusões (ZOMPERO; GONÇALVES; LABURÚ, 2017).

Nesse sentido, o planejamento pedagógico baseado em métodos representacionais variáveis relacionados a aspectos da neurociência buscam o desenvolvimento de habilidades comportamentais que incluem a cognição e a emoção dos estudantes (DIAS, 2014). Essas habilidades já estão amplamente difundidas em estudos científicos, e são denominadas como Funções Executivas (LEZAK, 1982), e a importância de sua promoção e desenvolvimento no âmbito educacional já reconhecida através de programas como o PIAFEX - Programa de Intervenção e Autorregulação e Funções Executivas (DIAS, 2014).

Conforme supracitado, essas funções são habilidades ligadas ao desenvolvimento cognitivo e emocional do indivíduo; segundo Lent (2010, p. 715): “razão e emoção são aspectos genéricos de um mesmo contínuo, e expressam as mais sofisticadas propriedades do cérebro humano".

O controle cognitivo envolve receber, processar e interpretar informações que entram pelos canais sensoriais simultaneamente. Essa tarefa é coordenada por uma importante região do nosso cérebro, o córtex pré-frontal, considerado o responsável pelo nosso comportamento inteligente (LENT, 2010). É importante salientar que essa região, assim como outras já mencionadas previamente, está conectada com várias outras em todo encéfalo, como núcleos talâmicos, o cerebelo, a amígdala, o hipocampo e o tronco encefálico (LENT, 2010). Estudos apontam que neurônios pré-frontais revelaram-se multimodais, sendo ativados pelos diferentes estímulos que recebemos, tais como visuais, auditivos, táteis, gustatórios entre outros (LENT, 2010). De fato, o córtex pré-frontal é definido como uma região cortical terciária, na qual diferentes modalidades de informação podem ser associadas. Cabe ao professor durante a prática pedagógica oferecer situações fundamentas em experiências ricas em estímulos diversos, que promovam a ativação desses neurônios e, consequentemente, novas sinapses (CARVALHO, 2011).

Portanto em uma abordagem educacional pluralizada, com enfoque em múltiplas representações conceituais, conforme Gardner, duas coisas acontecem:

Primeiro, torna-se acessível para mais alunos. Se alguns aprendem melhor ouvindo histórias, outros o conseguem fazendo trabalhos artísticos ou atividades em grupo 


\section{\#tear}

[...]. Em segundo lugar, uma educação pluralizada favorece uma compreensão mais ampla" (GARDNER, 2015, p. 35).

Conforme dito anteriormente, o estado de atenção implícita do indivíduo é extremamente importante para o processo de aprendizagem, e está relacionado ao desafio e ao prazer, que são estados comportamentais regulados por receptores dopaminérgicos ${ }^{2}$, o que sugere serem controlados pelo nosso sistema de recompensa através de vias mesolímbicas ${ }^{3}$ (LENT, 2010). Dessa forma, uma atividade que busque a participação ativa dos estudantes, na qual visualizem prazer/satisfação ao atingir o objetivo da atividade, deve ser vista de forma positiva entre os mediadores do processo ensino.

\section{Conforme Roberto Lent:}

[...] as atividades da razão que envolvem raciocínio lógico para a resolução de problemas e tomada de decisões, a fixação de objetivos e o planejamento das ações correspondentes, começam com a focalização da atenção para as informações que chegam, vindas do meio externo ou da própria mente" (LENT, 2010, p. 743).

Professores podem utilizar algum tipo de recompensa como estratégia motivacional, planejando a situação de aprendizagem juntamente àqueles elementos já reconhecidos como promotores de motivação: apresentar desafios, promover curiosidade, diversificar planejamentos de atividades, proporem competições (MEDEIROS; FIGUEREDO, 2010). Ainda, para o desenvolvimento das funções cognitivas é importante que os aprendentes tenham claro quais são os objetivos da atividade, e estejam conscientemente comprometidos com ela, entendendo sua importância para sua formação.

A neurociência aponta que o processo de amadurecimento do córtex pré-frontal pode se estender até ao final da terceira década de vida, ou seja, é necessário planejar qualquer atividade levando em consideração a faixa etária dos estudantes (CAMPOS, 2010). O cérebro dos adolescentes, longe de estar maduro, passa por extensas modificações estruturais bem além da puberdade, como revelam imagens de ressonância magnética funcional (OECD, 2007). Assim, o córtex pré-frontal ainda em desenvolvimento entre os adolescentes pode auxiliar no entendimento de seus comportamentos muitas vezes instáveis (OECD, 2007).

No entanto, as funções executivas não envolvem somente o processo cognitivo de cada indivíduo, mas também o seu processo emocional. Sabe-se que cada emoção tem um padrão fisiológico característico, mas adquire uma nuance própria em cada pessoa (LENT, 2010). Tanto positivas quanto negativas, as emoções podem provocar um estímulo positivo

\footnotetext{
${ }^{2}$ Receptores implicados em processo neurobiológicos tais como, a motivação, o prazer, a cognição, memória e aprendizagem (LENT, 2010).

${ }^{3}$ Tipo de via dopaminérgica (LENT, 2010).
} 
(prazeroso) ou negativo (desagradável), o que implica que se um estímulo está sendo reforçado pode ser percebido tanto como recompensa, como punição (LENT, 2010).

Assim como o córtex pré-frontal é uma região importante no processo do desenvolvimento cognitivo, a amígdala (ou complexo amigdaloide) é uma região do sistema nervoso central que tem papel chave nos disparo das reações emocionais, inclusive o medo (LENT, 2010). O medo é visto como um tipo de memória implícita ${ }^{4}$, armazenada em sinapses com alto grau de plasticidade, especialmente para a potenciação de longa duração ${ }^{5}$. Mas a amígdala também modula a memória explícita ${ }^{6}$ segundo a influência de estímulos emocionais relevantes. Essa modulação emocional é possibilitada pelas conexões que existem entre o complexo amigdaloide e o córtex que fica em torno do hipocampo (córtex entorrinal) (LENT, 2010). Ao longo da vida aprendemos a refrear nossos impulsos agressivos através da boa educação, do diálogo e da compreensão entre as pessoas. Por conta disso, o córtex pré-frontal pode ser considerado um modulador (geralmente um inibidor) da amígdala, controlando a sua influência sobre as estruturas que disparam as manifestações fisiológicas e os comportamentos emocionais (LENT, 2010).

Algumas habilidades cognitivas são consideradas importantes para o processo de ensino e de aprendizagem das ciências da natureza. Entre elas observar, registrar, analisar dados, comparar, perceber evidências, fazer inferências, concluir, aprimorar o raciocínio e argumentar. Portanto, ao se requisitar e aprimorar o exercício de habilidades cognitivas para investigação científica, necessariamente se está estimulando e desenvolvendo o uso de funções executivas (ZOMPERO; GONÇALVES; LABURÚ, 2017). A falta de um planejamento adequado com instrumentos que não visam explorar diversos aspectos de um mesmo conteúdo pode contribuir para uma aprendizagem deficiente, implicando no não desenvolvimento das habilidades supracitadas. Dessa forma, uma alternativa para os profissionais da educação seria voltar sua atenção sobre a importância das diferentes formas de metodologias de ensino, ao invés de se sustentar numa única modalidade de ensino, e em hipóteses que apontam a causa perante impedimentos neurológicos por parte dos estudantes (SILVA, 2015).

\footnotetext{
${ }^{4}$ Forma de memória que não precisa ser expressa por meio de palavras, mas é facilmente demonstrada na prática (hábitos, habilidades motoras e regras (LENT, 2010).

${ }^{5} \mathrm{Um}$ mecanismo de plasticidade neuronal dependente da atividade neural, que muitos acreditam ser um dos substratos celulares do processo de formação de memórias (LENT, 2010).

${ }^{6}$ Forma de memória que pode ser descrita por meio de palavras (LENT, 2010).
} 


\section{\#tear}

\section{Múltiplas representações como estratégia metodológica no ensino de ciências}

É necessário elucidar que a defesa da utilização de metodologias variáveis no ensino de ciências não tem por objetivo criticar determinado modelo de prática pedagógica, assim como não elenca hierarquicamente modos mais eficazes (BICA; ROEHRS, 2015). Duval (2006) apresentou, em um estudo sobre o ensino da matemática, a distinção de quatro tipos de representação e registrou que a variedade e o espaço cognitivo da representação convergem de acordo com o registro de origem e o registro de destino, permitindo definir algumas variáveis para analisar a complexidade cognitiva subjacente a qualquer atividade, seja para um objetivo de pesquisa, ou para um objetivo de educação (DUVAL, 2006).

É reconhecido que a aprendizagem do discurso científico pode ser potencializada quando associada à compreensão e à integração de diferentes formas de representação (KOZMA; RUSSEL, 1997; KEIG; RUBBA, 1993). Cada representação apresenta níveis de eficácia e fraqueza diferentes em relação à precisão e à capacidade de dar significado a determinado grupo de conceitos, dessa forma se faz necessária reflexão sobre quais representações utilizar na prática docente (KLEIN; LABURÚ, 2012).

O professor através do planejamento e da mediação deve propor, juntamente, aos estudantes, a tarefa de entender os diferentes aspectos das representações e seu uso integrado no momento em que estão aprendendo ciência. Eles têm necessidade de compreender que diferentes modos encerram distintos propósitos, como o caso, por exemplo, de uma representação gráfica, tabular ou algébrica, usadas para indicar medidas extraídas em um experimento para identificar a relação entre elementos (KLEIN; LABURÚ, 2012).

Uma mudança que vem ocorrendo ao longo do tempo é a presença e a utilização de imagens como forma de representação conceitual, se consolidando como um facilitador conceitual (GONZÁLEZ; ESCUDERO, 2015). No ensino de Biologia e Química, por exemplo, há uma crescente ampliação do emprego de imagens nos próprios livros didáticos, entre as quais encontram-se as representações de partículas microscópicas, os esquemas e as fotografias, e é visível a diferença na apresentação visual e na abordagem utilizada ao longo dos diversos capítulos (SANGIOGO; MARQUES, 2015).

Ainsworth (1999) aponta três razões para que ocorra essa integração entre as representações conceituais e a aprendizagem. Primeiramente, uma nova representação convém para complementar, confirmar ou reforçar conhecimentos passados. Segundo, uma nova representação propicia restrição e refinamento de uma interpretação. Finalmente, diferentes representações capacitam o estudante a identificar um conceito abstrato através de 


\section{\#tear}

diferentes modos representacionais, e ainda serve como um elo entre o conhecimento prévio e o conhecimento novo que está sendo apresentado para o aprendiz (KLEIN; LABURÚ, 2012).

\section{Considerações Finais}

Estudantes possuem diferentes motivações e podem aprender de diferentes modos, de acordo com suas experiências prévias. Também variam em suas habilidades mentais específicas, ritmos de aprendizagem, nível de motivação e interesse para uma determinada disciplina. Suas experiências prévias e/ou vínculos mantidos com o grupo social ao qual pertencem também são fatores que influenciam na qualidade e na profundidade da aprendizagem (LABURÚ; BARROS; SILVA, 2011). Por conta disso, torna-se questionável um esquema educacional baseado num único formato representativo que somente dá conta das necessidades de um tipo particular de aluno ou grupo de alunos, e excluem outros (LABURÚ; BARROS; SILVA, 2011). A multiplicidade semiótica e funções de comunicação devem ser aproveitadas no âmbito didático em função das necessidades cognitivas individuais (PERALES PALLACIOS, 2006).

Concomitantemente, vivemos em mundo envolvido e dependente de ciência e tecnologia, se fazendo necessário otimizar o ambiente escolar e oportunizar aos estudantes instrumentos e ferramentas planejados sob um viés cognitivo e multirepresentacional, para compreender o mundo moderno. Realizando uma interface das pesquisas do campo da neurociência, utilizando-se de seus conceitos inovadores em prol de um ensino mais centrado no aprendizado, considerando o corpo e a mente dos estudantes de forma mais integralizada (FERNANDES et al., 2015).

Tais reflexões delineiam prioridades para as políticas educacionais, sendo necessário pensar em uma estrutura escolar menos arbitrária, que vise recolher toda a gama de potencialidade humana (PINKER, 2004). Estudantes, assim como qualquer pessoa, possuem diferentes personalidades, vivenciaram diferentes trajetórias e experiências, e, assim, reagem diferentemente às personalidades das outras pessoas, inclusive a do professor, e aos diversos estímulos que recebem, incluindo os relacionados ao aprendizado escolar.

\section{THE CONVERGENCE BETWEEN NEUROSCIENCE AND THE MULTIPLE REPRESENTATIONS FOR SCIENCE TEACHING}

Abstract: The teaching of sciences presupposes a set of different symbols and forms of communication. Because of this, it becomes questionable an educational schemed based on a single representative format. As pointed out by international evaluation programs and our curricular guidelines, the process of learning science involves a representational challenge in a 
variety of contexts. In this sense, there is a line of research in the area of science teaching, denominated multiple representations, which advocate the use of different forms of communication in the teaching and learning process. Recent studies of neuroscience point to some results that fit into this perspective, linking fundamental knowledge of the neurobiological bases of learning, of memory, of emotions, above all respecting the students cognitive individuality. This work presents points of convergence between reference points of science teaching and postulates of neuroscience field, in which both can come to support and contribute to the process of teaching practice in science teaching.

Keywords: Neuroscience. Multiple Representations. Science teaching. Cognition. Memory.

\section{Referências}

AINSWORTH, S. The functions of multiple representations. Computers \& Education, 33, p. 131-152, 1999.

BARBOSA, J.U. et al. Analogias para o ensino de bioquímica no ensino médio. Revista Ensaio, 14 (1), p. 195-20, 2012.

BICA, M.S.N.; ROEHRS, R. A abordagem dos conceitos de substância, mistura e densidade utilizando os fundamentos das múltiplas representações. Experiências em ensino de ciências, 10 (2), 2015.

BRASIL. Ministério da Educação. Secretária de Educação Básica. Diretoria de Currículos e Educação Integral / - Diretrizes Curriculares Nacionais Gerais da Educação Básica. Brasília: MEC, SEB, DICEI, 2013.

CAMPOS, A.L. Neuroeducación: uniendo las neurociencias y la educación em la busqueda del desarrollo humano. La educ@ ción, n.143, 2010.

CARMO, E. A. Analogias como instrumentos úteis para o ensino do conteúdo químico no nível médio. Belém: UFPA, 2006. Dissertação (Mestrado em Educação e Matemática) Núcleo Pedagógico de Apoio ao Desenvolvimento Científico, Universidade Federal do Pará, Belém, 2006. Disponível em:

$<$ http://repositorio.ufpa.br/jspui/bitstream/2011/1831/5/Dissertacao_AnalogiasInstrumentosUt eis.pdf>. Acesso em: 17 jun. 2017.

CARVALHO, F.A.H. Neurociências e Educação: uma articulação necessária na formação docente. Trabalho, Educação e Saúde, v.8, n.3, p. 537-550, 2011.

CHIESA, B. Um ABC do Cérebro. Revista Neuroeducação, São Paulo, Segmento, n.1, p. 43, 2012.

DEHAENE, S.; COHEN, L. The unique role of the visual word form area in reading. Trends in cognitive sciences, v.15, n.6, p. 254-262, 2011.

DIAS, N.M. Promoção do desenvolvimento de funções executivas em crianças: apresentação do Piafex e evidências de estudos nacionais. I Seminário Tecnologias Aplicadas a

Educação e Saúde, UNEB, campus I, out. 2014.

DUVAL, R. A cognitve analysis of problems of comprehension in a learning of mathematics. Educacional Studies of Mathematics, 61, p.103-131, 2006. 
FERNANDES, C.T. et al. Possibilidades de aprendizagem: reflexões sobre neurociência do aprendizado, motricidade e dificuldades de aprendizagem em cálculo em escolares entre sete e doze anos. Ciência \& Educação, v.21, n.2, p. 395-416, 2015.

FREITAS, D.P.S.; MOTTA, C.S.; MELLO-CARPES, P.B. As bases neurobiológicas da aprendizagem no contexto da investigação temática freiriana. Trab. Educ. Saúde, n.13, v.1, p.109-122, 2015.

FRITH, U.; MAGUIRE, E.; BISHOP, D. Neuroscience: implications for education and lifelong learning. Royal Society, 2011.

GARDNER, H. As inteligências Múltiplas, Revista Neuroeducação, n.3, p.35, 2015.

GARVETT, M.M.; DOLAN, R.J.; BEHRNS, T.E.J. A map of abstract relational knowledge in the human hippocampal-entorhinal cortex. eLife, 6, p. 1-20, 2017.

GONZÁLEZ, S.B.; ESCUDERO, C. El modelo atómico y las representaciones de los adolescentes. Experiências em Ensino de Ciências, v.10, n.3, 2015.

HERCULANO-HOUZEL, S. Neurociências na educação. Rio de Janeiro: CEDIC, 2009.

IZQUIERDO, I. Memória. 2 ed. Porto Alegre: Artmed, 2011.

KEIG, P. F.; RUBBA, P. A.Translation of representations of the structure of matter and its relationship to reasoning, gender, spatial reasoning and specific prior knowledge. Journal of Research in Science Teaching, Hoboken, v.30, n.8, p. 883-903, 1993.

KHOIRIYAH U. et al. Enhancing students' learning in problem based learning: validation of a self-assess- ment scale for active learning and critical thinking. BMC Med Educ 15, 2015.

KLEIN, T.A.S.; LABURÚ, C.E. Multimodos de Representação e teoria da Aprendizagem Significativa: Possíveis Interconexões na Construção do Conceito de Biotecnologia. Revista Ensaio, v.14, n.2, p.137-152, 2012.

KLEIMAN A.M. et al. Generative retrieval improves learning and retention of cardiac anatomy using transesophageal echocardiography. Anesth Analg, 124, p. 1440-1444, 2017.

KOZMA, R. B.; RUSSELL, J. Multimedia and understanding: Expert and novice responses to diferente representations of chemical phenomena. Journal of Research in Science Teaching, Hoboken, n. 34, p. 949-968, 1997.

LABURÚ, C.E.; BARROS, M.A.; SILVA, O.H.M. Multimodos, Múltiplas Representações, Subjetividade e Aprendizagem Significativa. Ciência \& Educação, v.17, n.2, p. 469-487, 2011.

LENT, R. Cem bilhões de neurônios? Conceitos fundamentais de neurociência. 2 ed. São Paulo: Atheneu, 2010.

LEZAK, M. D. The problem of assessing executive functions. International Journal of Psychology, v.17, n.1-4, p. 281-297, 1982. 


\section{\#tear}

LUYTEN, S. M. M. Introdução. Salto para o futuro - História em quadrinhos: um recurso de aprendizagem, boletim 1, ano XXI, p. 5-9, 2011.

MEDEIROS, T.G.; FIGUEREDO, C.J. O papel das recompensas como estratégia motivacional em sala de aula de inglês. Revista de Educação, Linguagem e Literatura da UEG-Inhumas, v.2, n.1, p. 53-73, 2010.

MELLO-CARPES, PB; LARA, M. V. S. Percebendo e interpretando o mundo - mecanismos de codificação da informação. In: Pâmela Billig Mello-Carpes. (Org.). A fisiologia presente em nosso dia a dia: Guia prático para o profissional da saúde. 1ed. São Paulo: Livrobits, 1, p. 117-130, 2012.

MELTZOFF, A.N. et al. Foundations for a new Science of learning. Science, 325, p.284-288, 2009.

MOREIRA, M.A.; MANSINI, E.F.S. Aprendizagem Significativa: a teoria de David Ausubel. São Paulo: Centauro, 2009.

OECD, Understanding the Brain: The Birth of a Learning Science, Paris: OECD, 2007. Disponível em < http://www.oecd.org/site/educeri21st/40554190.pdf >. Acesso em: 10 mar. 2017.

PERALES PALLACIOS, F. J. Uso (y abuso) de la imagen en la enseñanza de las ciencias. Enseñanza de las Ciencias, v.24, n.1, p. 13-30, 2006.

PEREIRA, M.V.; MOREIRA, M.C.A. Atividades prático-experimentais no ensino de física. Caderno Brasileiro no Ensino de Física, v.34, n.1, pag. 265-277, 2017.

PINKER, S. Tábula Rasa: a negação contemporânea da natureza humana. São Paulo: Companhia das Letras, 2004.

PISA 2012. Assessment and analytical framework: mathematics, reading, science, problem solving and financial literacy. Paris: OECD, 2013. Disponível em: < http://dx.doi. org/10.1787/9789264190511-en >. Acesso em: 17 abr. 2017.

SANGIOGO, F.A.; MARQUES, C.A. A não transparência de imagens no ensino e na aprendizagem de química: as especificidades nos modos de ver, pensar e agir. Investigações em Ensino de Ciências, v.20, n. 2, p.57-75, 2015.

SILVA, C.L. Vygotsky e a neurociência, Revista Neuroeducação, n.4, p.. 652015.

SILVA, E.L.; MARCONDES, M.E.R. Materiais didáticos elaborados por professores de química na perspectiva CTS: uma análise das unidades produzidas e das reflexões dos autores. Ciência \& Educação, v.21, n.1, p.65-83, 2015.

SILVA, L. L.; TERRAZAN, E. A. O uso de analogias no ensino de modelos atômicos. In: Simpósio nacional de ensino e física, 16, 2005. Rio de Janeiro. Anais eletrônicos. Rio de Janeiro: SBFísica, 2005. Disponível em: < http://www.sbf1.sbfisica.org.br/eventos/snef/xvi/sys/resumos/T0666-1.pdf > . Acesso em: 10 set. 2017. 
SOARES, M.H.F.B. Jogos e atividades lúdicas no ensino de química: teoria, métodos e aplicações. In: Encontro Nacional de Ensino de Química, 14, Curitiba, UFPR, 2008.

SOSA, P. et al. Active memory reactivation previous to the introduction of a new related content improves students' learning. Advances in Physiology Education, 42, p. 75-78, 2018.

UCHO, A.M.; FRANCISCO JUNIOR, W.E.; FRANCISCO, W. Produção e avaliação de uma história em quadrinhos para o ensino de química. XVI Encontro Nacional de Ensino de Química e X Encontro de Educação Química da Bahia. Salvador, jun. 2012.

ZOMPERO, A.F.; GONÇALVES, C.E.S.; LABURÚ, C.E. Atividades de investigação na disciplina de Ciências e desenvolvimento de habilidades cognitivas relacionadas a funções executivas. Ciência \& Educação, v.23. n.2, p. 419-436, 2017. 